SOCIAL WORK IN GENERAL PRACTICE BY

\author{
MADGE DONGRAY, B.A., A.M.I.A. \\ Social Worker, Darbishire House Health Centre, \\ University of Manchester
}

Considerable interest to-day is focused on the treatment and management of stress and strain and emotional disturbance in general practice. Opinions vary regarding the extent and importance of this problem, but few would deny that the family doctor, whether he likes it or not, is faced with a variety of social and emotional problems on which patients seek his advice and help. This raises the question of how far, in his capacity as medical adviser, he is concerned with them, and, if he feels rightly concerned, the question of what sort of help he can be expected to give. Here again opinions differ, ranging from the few doctors who consider these problems still outside their scope to those who consider the general practitioner should " do it all." The abundance of articles and correspondence on the subject, however, suggests that many family doctors feel a need for some sort of help in dealing with this aspect of their work, and some have written interesting accounts of the particular form of help they have chosen or have been able to find (Balint, 1957 ; Saville, 1957 ; Davis, 1957 ; Chalke and Fisher, 1957 ; Backett et al., 1957).

At Darbishire House, Manchester University Health Centre, it was decided in June, 1955 , for good or ill, to attach a trained social worker to the group of four family doctors practising from the centre and serving approximately 12,000 patients in a closely populated city area. I would like to say a little about this experiment.

\section{First Steps}

Experiment it certainly was, as the doctors had not worked directly with a social worker before and I had not worked in general practice. At the outset none of us had any clear idea of the sort of work which might be necessary or possible. The doctors knew that 1 had been a hospital almoner and had had some experience of child guidance, and it was agreed that in the first place they should refer to me any problems presenting social or emotional factors with which they thought or hoped I might be able to help.

During the first few months, which were largely spent in getting to know each other and learning to appreciate each other's points of view, two difficulties confronting the busy practitioner became steadily clearer; one was connected with the rapid advance in scientific medicine over the past 20 to 30 years, and the other with the growth of the social services over the same period of time.

The first difficulty is best illustrated by an account by one of the doctors of the tremendous change which the introduction of antibiotics had made in the management of pneumonia within his lifetime. Twenty years ago there was little the doctor could do but wait and hope until the crisis passed and then watch over a long, slow convalescence. Now the illness is usually arrested by a few injections, which take a minute or two to give and which can sometimes be delegated to the nurse. The relief from a heavy burden of responsibility in the doctor can readily be appreciated, but his personal contact with the patient and family is immeasurably curtailed and treatment tends to become a service rendered by the doctor rather than an experience lived through with the family. One suspects that the doctor may feel less helpless, but not the family. The mother who said, "We liked the old doctor ; he used to talk to us about Johnny; the new one just sticks needles into him," was, I think, voicing her feeling that she no longer. had any significant part to play in the treatment of her child. This does not, of course, mean that the new and the old approach cannot be combined, but perhaps they tend, at present, to remain distinct and are often kept so by the pressure of present-day practice and perhaps for other less obvious reasons.

The second difficulty concerns the rapid growth in the social services and revolution in social legislation over the same period of time. This often makes the doctor feel that management of his cases in a truly personal way has been taken out of his hands. With the best will in the world he could not be expected to be fully conversant with this side of the picture as well as keeping abreast of development in the medical sphere.

Thus doctors and patients alike tend to complain of a dwindling sense of responsibility and consideration towards each other in an age when pain and suffering are no longer accepted passively as the inevitable lot of man, and there is a general feeling that for any misfortune whatever there must be a remedy somewhere in somebody's hands.

Our experience at Darbishire House has, I think, shown that in both these spheres a social worker can give useful assistance to the doctor.

\section{Using the Social Services Efiectively}

Part of the social worker's basic equipment is a sound knowledge of the social services, both statutory and voluntary. In addition it is her duty to know clearly how these services actually operate in the district in which she works, so that she can interpret and explain them to the doctor and patient, both of whom tend to find them confusing. She can then assist the doctor to choose the agency most likely to help his patient, and can also belp him to prepare and assist the patient to make good use of the facilities offered.

Take the simple example of advising a patient to attend a Ministry of Labour rehabilitation unit. It is important that the doctor distinguishes this service from Government training schemes, otherwise there is a danger of raising false expectations in the patient; it is useful to be able to answer some of the patient's questions about the allowances he will receive and to understand that he will not be guaranteed a job on completing the course, although the Ministry of Labour will do everything in its power to place him. It is helpful to understand the sort of experiences he may expect during the first few weeks at the unit: for the timid or truculent, for example, the aptitude tests can be a source of anxiety or irritation which may bring the patient back to complain at the surgery.

A patient who undertakes such a course free from avoidable misconceptions regarding its purposes is likely to make better use of the opportunity and to feel more confidence in the doctor who suggested it, and the social worker can often detect the hidden misconceptions which prevent patients from using the appropriate social service. For instance, a widow was found to be afraid to apply for National assistance because her husband had at one time drawn assistance under false pretences and she feared she would be penalized for his sins. A girl would not take out an affiliation order, believing that the court would send her to Borstal for having an illegitimate child while she was still under 21.

Doctors can attend lectures, read pamphlets, and pay visits of observation, but these time-consuming activities are, we think, no substitute for the opportunity to learn from repeated application and practice in collaboration with a social worker directly attached to the group.

\section{Understanding Family Relationships}

The social worker can often supplement the doctor's knowledge and understanding of family problems with her special skills in interviewing and understanding of personal 
relationships. In an area such as ours it is not possible for the doctor to know all his patients and families intimately. Families move into and out of the district, split up, and come together again with surprising frequency. The doctor may be called suddenly to attend a family about which he knows nothing but where he senses underlying problems. Sometimes only one member of a family is registered with him, which makes it difficult to get a clear picture of the family as a whole ; or the patient may be living alone, often as a result of intolerable conflicts with his family. In such cases an unhurried interview in which the patient does most of the talking and the social worker most of the listening, or a home visit to meet other members of the family, can illuminate the situation and enable the doctor to adopt the most helpful attitude towards the patient and family.

Young Mrs. X had been registered with the doctor for a few months, during which she had appeared repeatedly at the surgery seeking help with trivial ailments in herself and her baby daughter. The doctor was disturbed by her seemingly unreasonable demands on his time and patience, and asked me to see her.

She told a story of a grossly deprived and insecure childhood, and finished by saying, "The doctor is really a nice fatherly soul, isn't he?" This suggestion that she was seeking from the doctor a relationship which she had never had from her parents helped us to come to terms with our own attitude towards her.

Although her basic need for a good parent could never be fully satisfied by the doctor or anyone else, it was helpful that the doctor could understand this need and could tolerate and accept her demands without anxiety. It would have been no good to lecture her on being overanxious, but by accepting her anxiety as real and understandable he could give her a measure of reassurance and security which she should be able to communicate to her child, and, in a slight degree, prevent this child suffering as severely as she had done herself.

This sort of help may also be needed by families who have been registered with the doctor for some years and whose contact with him has been slight because they are seldom ill and send for hım only in a crisis or because the management of the ill member of the family is in the hands of a hospital or other organization. This was the case with Mrs. Y, who had a spastic child. Jane, aged 2, and a normal healthy boy, John, aged 7 months. Mrs. Y had attended hospital regularly with Jane ever since she was a baby and also went to the child welfare centre with John, and she rarely sent for the family doctor. However, he was called in when John had bronchitis, and noticed that Mrs. Y spoke about Jane in -such a way that he asked me to call and assess the situation. mentioning that the undesirable housing conditions made the problem of looking after Jane very difficult.

During my visit I gradually realized that Mrs. Y really had little idea of what to expect from Jane and did not seem to have grasped the implications of her condition. She held Jane up to show me her scissor gait, then put her on the floor, saying, "Look, she won't sit up." She put Jane in a chair with John, an extremely robust and vigorous child, and got annoyed with her for flopping over on to him. Mrs. $Y$ was a young immature woman, but not by nature callous or unkind.

I discussed this with the doctor and suggested it would be helpful for someone to explain the child's condition to the mother and, if possible, to the father also, since Mrs. Y did not strike me as being capable of passing on to her husband, without distortion, whatever the doctor might tell her, and since any mother with a severely handicapped child needs the utmost support from her husband and this is more likely to be fostered by including him in consultations. Mrs. Y must certainly have received considerable information and advice already, but she had clearly been unable to accept and comprehend the nature of Jane's disability while she was still a baby, until John, at 7 months, had started to outstrip the 2-year-old Jane. It was then the family doctor to whom she voiced her anxiety.

The housing problem did undoubtedly add to her difficulties, but, in spite of application to the housing department, there was no hope of an early solution. However, after a long discussion with the doctor, Mr. and Mrs. Y thanked him for his help, and we learned a little later that they were saving a deposit for a new house.

\section{Long-term Casework with Families}

The foregoing examples mainly illustrate help I was able to give to the doctor; the next example is a little different in that the help was given more directly and continuously to the family.

Mrs. $Z$ had been unfortunate with her children. After carrying her first baby eight months she was delivered of a macerated foetus; her second child, Paul, was a mongol ; her third child, Douglas, developed epileptic fits at $2 \frac{1}{2}$. When I first met them Paul was 5 years old and attending an occupation centre daily; Douglas was 4 , and Mrs. Z was complaining of his excessive temper tantrums and destructiveness.

During a visit to the home I saw both parents, who spent much time demonstrating to me, in the presence of Douglas, what a terrible child he was, with the natural result that he behaved accordingly. The mother was sure he was going to be delinquent; the father certain he was " mad" and would never allow his teachers to teach him anything if they succeeded in getting him to school at all. The father said, half provocatively, that friends had advised him to take the child to a psychiatrist, and the mother said that, although she had great faith in the doctor, they had never had "specialist" advice - she seemed to favour a medical or neurological consultation. In fact, the child's attacks were well controlled with phenytoin sodium and phenobarbitone, and he had only an occasional fit.

I suggested that, if the family doctor agreed, we could refer them to the psychiatric department of the children's hospital, where there was a close liaison with the neurological department. They were obviously in two minds about this, but agreed 1 should consult the doctor. From their manner it seemed to me that these two highly anxious, ill-informed, and guilty parents were unlikely to make good use of this offer without further help and encouragement. The mother poured scorn on those who had already attempted to help her with Paul, and the parents clearly felt threatened by the idea that anyone could do better with their children than they. On the other hand, I felt that behind all this display of aggressive anxiety was considerable positive feeling.

A report was sent to the hospital, and, pending an appointment, I visited the mother fortnightly, seeing her for about an hour. At first she was aggressively casual, but on the third visit this attitude collapsed as she told me how difficult it was to be the mother of the only two children in the street who were "queer"-how she felt people criticized her for being too severe or too lenient with them, making her feel she ought not to have had them at all or should have put them in a home. Gradually she was able to discuss her wish to reject her children and her guilt about it, as well as her wish to cherish them, and how both she and her husband wondered why this had happened to them and who was to blame. She had rather resentfully given up work when Douglas started having fits and had taken to minding three normal children under 3 years of age from 8 a.m. to 5 p.m. five days a week in a house which was barely big enough to hold her own family. She denied emphatically that Douglas could feel jealous of these children, although he was often aggressive towards them; nor could she admit any rivalry between Douglas and Paul, as "she treated them both alike although Paul was worth ten of Douglas." Gradually, however, she began to watch Douglas's behaviour towards the other children and to admit its meaning; and she also began to realize that it was impossible 
to treat a mongol child and an intelligent epileptic one exactly alike and to see that it must be difficult for Douglas to have an older brother who will remain a baby while he has to grow up.

Mrs. $\mathrm{Z}$ attended the psychiatric department in due course and obtained some satisfaction from learning that Douglas was of normal intelligence and some measure of reassurance about handling his tantrums and understanding of his type of epilepsy. She would not agree to attend more regularly than at three-monthly intervals, and, after consultation with the psychiatrist and his social worker, I continued to visit the home, extending the intervals between interviews as the situation improved.

The family was helped to tackle its housing problem, and there is a definite hope of removal within 18 months. This seems to have spurred the father on to get a better job, but the mother has begun to talk about loneliness on a new estate. Facing a new set of neighbours may well arouse some of her old fears, so we will try to keep in touch with her for a while round the removal time.

It is not possible to give an account of all that has been discussed or has happened during the 12-months association with this family, but certain changes have occurred: medication for Douglas has been reduced and he has not had a fit for nine munths; and he started school recently without undue disturbance.

The precise reasons for these changes are open to dispute, although this is not the only case in which a gradual reduction in the need for medication has followed a combined attempt by the doctor and social worker to understand the emotional stresses in a family in which the patient has been diagnosed as having epilepsy. The situation is by no means stable even now, but the mother often speaks of Douglas as "really a very good boy" and the relationship between them seems calmer and warmer. We have yet to see if the improvement will last, as my visits become less frequent and we cannot definitely claim to have prevented more serious and chronic trouble later, although, judging from the accounts we often hear about the distressing early experiences of adult epileptics with disturbed personalities whose families do not appear to have had similar help, we hope that some lasting benefit has been given in this case.

The tensions in this family had been building to for a long time-at least from the shock of Mrs. Zs first disastrous pregnancy. The problem centred in feelings of failure and inadequacy in having produced three damaged children-an extremely difficult situation for any couple to face, much less Mr. and Mrs. Z, who had themselves both suffered considerable emotional deprivation in their own childhood. Many workers had attempted to help them piecemeal with these problems, but what the family most seemed to need was a steady relationship with one person who could accept and tolerate the situation at its most explosive and encourage them to talk freely without fear of criticism or coercion ; someone, moreover, who could act as a focusing point, helping them to integrate the separate experiences with the doctor, psychiatrist, health visitor, and teacher, and with relatives and neighbours.

This sort of relationship, I suggest, could not have been supplied by the doctor even though the problem in this case was directly associated with medical care, but it was most appropriately handled by someone working in close co-operation with the doctor.

\section{Conclusions}

In conclusion I would like to summarize some advantages which appear to belong particularly to a setting in which a social worker is attached directly and exclusively to a group of family doctors.

\section{Accessibility}

Help is available on the spot whenever the doctor is puzzled or disturbed by a particular problem, and consequently he tends to seek it more readily than if this were to involve considerable time and effort in seeking it elsewhere. This is particularly so where the problem does not fall easily into a case for referral to any of the well-known social agencies, but where the dominant need is for an assessment of the situation on which to base a plan of help.

\section{Participation in Group Discussion}

Informal group discussion over morning coffee will often centre in a particular patient or family ; more often it will concern the wider aspects of social care such as housing or employment policy, care of handicapped children or old people, or such perennial points of dispute as "malingering," use and abuse of the Health Service, the "unreasonable "patient, the "problem" family. The social worker can often bring a fresh perspective to bear on these subjects or provide information in the light of which judgments can be confirmed or modified.

\section{Interpretation of the Aims and Limitations of Social Work}

During the early months of my appointment the attitude of the doctors to me (as a social worker and not as a person) swung from scepticism about the value of social work in general to completely unrealistic demands on my resources. My own feelings were naturally coloured by the anxiety of working in a new setting, but it seemed to me that I was expected as " a nice motherly soul " to perform miracles which the psychiatrist had failed to produce; as a "strong right arm" to the doctor to wrest from the authorities houses for all the ill-housed, jobs for all the unemployed ; as an "expert" to clean up and re-educate problem families of long standing; in short, to relieve the doctor of all those painful situations in which he felt unable to be effective in his own right. Those who complain most loudly that social workers spoon-feed their clients and sap their sources of self-help and initiative sometimes demand just this from workers with whom they come in contact.

It was only gradually that we saw that the doctor and social worker must pool their resources and think about their work together in terms of the achievement of reasonable expectations and limited aims. We had to distinguish between what the doctor and social worker might want and what the patient wanted; to examine the values and principles which guided our work and to ask whether disappointing results arose from inadequacies within ourselves, the families, or the social system, or from factors about which we still have little knowledge. To cure sometimes, to relieve often, and to comfort always could then be accepted as applicable to social work as it is to medicine. The more realistic conception of social work aims and methods achieved through daily discussion and experiment can then be transferred to the relationship between the doctor and other social workers outside the group whom the doctor may wish to contact on his own initiative.

\section{Exploration of the Role of the Social Worker as Colleague of the Doetor}

Patients who consult the doctor on social or emotional problems or who present symptoms which appear to be connected with such difficulties may, I think, be said to have chosen the doctor as a source of help rather than anyone else. They are therefore likely to have strong feelings about any attempt on the doctor's part to suggest they look elsewhere for aid even though they may clearly be asking for the sort of assistance the doctor does not feel qualified to give. If the doctor's own conception of social work is not clear he will hesitate to redirect his patients but remain uneasy at being unable to help them. To have acquired an informed attitude towards social work as described in the last section is therefore helpful, but the strength of the patients' feeling towards the doctor has also to be reckoned with. Too hasty a referral to the social worker may be interpreted as a rejection, and we have learned from experience that it is only when the patient feels assured that the doctor has taken his trouble seriously that he can 
tolerate the idea of discussing it with someone else, whom the doctor can then introduce as a colleague, supplementing and not supplanting the aid he offers. In other words, the social worker becomes a sort of extension of the doctor, and patients are then able to accept her as an integral part of the service.

The patient's loyalty almost inevitably remains with the doctor. I well remember the slight shock I experienced when a patient whose problem had been satisfactorily resolved said to me, "the old 'Doc' worked jolly hard on that problem "-my own contribution had been apparently incidental. Our close association has made both the doctors and me very much more aware of the feeling content of the doctor-patient relationship and consequently able to use it more effectively.

\section{Discovering Unmet Need in General Practice}

It has been shown from the examples quoted in this article that some of the patients and families were already in touch with other workers. Mrs. Y, for example, was known to the staff at the welfare clinic, to the specialist, the physiotherapist, and possibly the almoner at the hospital ; Mrs. $\mathrm{Z}$ was being visited at intervals of three to six months by the health visitor responsible for the care of children under 5 and by another who supervised the baby-minding; she was also known to the school health and education department in respect of the mongol child. The needs of the family as a whule, however, had either not been recognized by the other workers, each of whom gave particular help with particular problems, or, if they were recognized, it had not been possible, for one reason or another, for them to give the overall help needed. Particularly in the case of Mrs. $Z$ there was a need for one person to undertake the job of standing alongside the family, co-ordinating their experiences in seeking belp with their problem; and this sort of need appears to us to occur more often than suspected in general practice. This was also recognized during a survey of a general practice carried out by the Social Medicine Research Unit of the Medical Research Council in 1953 (Backett et al., 1954). "This is not just a question of better co-ordination of the services ... the need is for a person, someone with professional training and skill, who can help people by means of a casework relationship to use their own and the community's resources in tackling their problem" (Shaw, 1954).

\section{Opportunities for Preventive Work}

The family doctor is often in a unique position for observing the earliest signs of social and emotional breakdown. Particularly in the case of mothers and babies, he witnesses early signs of anxiety and stress which, left unrelieved, may have serious repercussions in their emotional development and future happiness. Each time the doctor and social worker collaborate in analysing and assessing family needs and tensions the importance of relieving early signs of stress becomes more apparent. Until recently, at any rate, social workers have been made more aware of this in their training than medical students in theirs, but $I$ think it is clear from the examples quoted here that unless both the doctor and the social worker appreciate the importance of this aspect of family care on equal terms little can be achieved.

Hence, for the time being at least, there is much to be said in favour of providing the general practitioner with an opportunity of working with a social worker in closer relationship than has hitherto been the custom.

\section{REPERENCES}

Backett. E. M., Heady, J. A., and Evans, J. C. G. (1954). Brit. med. J., 1,

- Maybin, R. P., and Dudgeon. Y. (1957). Lancet, 1, 37.

Balint. M. (1957). Brit me.t. J 1, 156.

Chalke, H. D., and Fisher, M. (1957). Lancet, 2, 685 .

Davis, N. $\left(195^{-}\right)$. Ibid.. I. 160

Saville, P. R. (195-), Brit. med. J. 1, 158

Shaw. L. A. (19.44). "The Need for Social Casework in the Setting of General Practice." Case Conference, vol. 1, No. 5.

\section{RHEUMATIC DISEASE AND INDUSTRY}

[From a Special Correspondent]

A joint meeting of the Empire Rheumatism Council and the Association of Industrial Medical Officers was held at the Royal Society of Medicine on October 30 as part of the latter society's 84th meeting. The Chairman, Dr. W. S. C. COPEMAN, opening the discussion, drew attention to the importance of the rheumatic diseases in industry. This group of diseases was second only to respiratory illness as a cause of absence from work.

\section{Field Surveys}

Professor J. H. Kellaren, director of the Rheumatism Research Centre of Manchester University, said that the study of rheumatic diseases had in the past been greatly hampered by the lack of diagnostic definitions-from the eighteenth-century belief that most musculo-skeletal pains were gouty to the nineteenth-century concept of rheumatic fever as an all-embracing rheumatic process. Two recent developments had been of the greatest importance hereradiology and serology. Radiology had enabled rheumatoid arthritis to be distinguished from what he preferred to call osteoarthrosis ; and, later, other polyarthritides such as spondylitis, Reiter's disease, and psoriatic arthropathy had come to be defined. Serological work had shown that rheumatoid arthritis is associated with a macro-globulin which appeared to be specific, and that this might be associated with visceral, vascular, and cutaneous manifestati $n$ s of the disease. Biochemical techniques might well add further knowledge. These developments had enabled field workers to gather accurate information about the prevalence and incidence of various forms of chronic rheumatic disease. Professor Kellgren then described the procedure used in some of these surveys, emphasizing the difficulties of relying on only clinical diagnostic criteria. Many of these difficulties did not arise in radiological and serological studies. Radiological surveys had the advantage that standardization could be achieved, observer-error studies could be carried out, and the films could be kept as a permanent record. Serological studies had also produced results of great value. He cited the familial aggregation of the rheumatoid serum factor as an example, and suggested that this might be analogous to the hyperuricaemia of gout. From the epidemiological standpoint there were two main groups-those with the generalized changes of osteoarthrosis and disk generation, the most important numerically, and, secondly, those with inflammatory polyarthritis. For both of these groups we now had the techniques and equipment to study them in industry. Interesting variations in prevalence had already been noted - for example, as between rural and urban populations in South Wales.

Dr. J. S. LAWRENCE, director of the Empire Rheumatism Council's mobile field unit, said that industry was concerned not only with direct environmental factors but also with absenteeism due to rheumatic diseases generally. With an ageing population the latter would become increasingly important. He quoted National Health Insurance statistics for 1953-4, which showed an annual loss of 28 million mandays from rheumatic disease alone. After reviewing the role of the rheumatic diseases in various industries, he described a survey designed to investigate the prevalence of rheumatism in miners. This showed a clear association between the severity of $x$-ray changes in the lumbar spine and the complaint rate of back-hip-sciatic pain. A further survey had then been conducted to study possible occupational factors, and this had shown an association with back strain, other postural factors, and exposure to damp conditions. He believed that the heavy toll of rheumatic disease in miners was largely preventable, mainly by increased mechanization, which need not, as it was inclined to do at present, involve the use of still heavier equipment. Turning to rheumatoid arthritis, he said there were evidently considerable regional differences. This disease affected $3.3 \%$ 